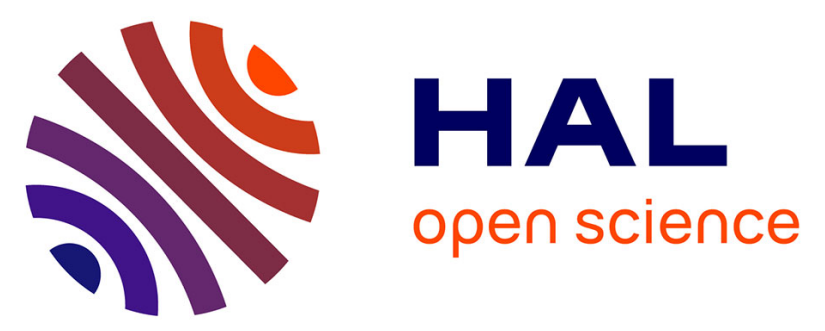

\title{
Large scale micro-structured optical second harmonic generation response imprinted on glass surface by thermal poling
}

G Yang, Marc Dussauze, Vincent Rodriguez, Frédéric Adamietz, Nicolas Marquestaut, K. L. N. Deepak, David Grojo, Olivier Uteza, Philippe Delaporte, Thierry Cardinal, et al.

\section{To cite this version:}

G Yang, Marc Dussauze, Vincent Rodriguez, Frédéric Adamietz, Nicolas Marquestaut, et al.. Large scale micro-structured optical second harmonic generation response imprinted on glass surface by thermal poling. Journal of Applied Physics, 2015, 118 (4), pp.043105. 10.1063/1.4926866 . hal01199509

\section{HAL Id: hal-01199509 \\ https://hal.science/hal-01199509}

Submitted on 10 Nov 2021

HAL is a multi-disciplinary open access archive for the deposit and dissemination of scientific research documents, whether they are published or not. The documents may come from teaching and research institutions in France or abroad, or from public or private research centers.
L'archive ouverte pluridisciplinaire HAL, est destinée au dépôt et à la diffusion de documents scientifiques de niveau recherche, publiés ou non, émanant des établissements d'enseignement et de recherche français ou étrangers, des laboratoires publics ou privés. 


\section{Large scale micro-structured optical second harmonic generation response imprinted on glass surface by thermal poling}

Cite as: J. Appl. Phys. 118, 043105 (2015); https://doi.org/10.1063/1.4926866

Submitted: 12 May 2015 - Accepted: 04 July 2015 • Published Online: 24 July 2015

G. Yang, M. Dussauze, (D) V. Rodriguez, et al.
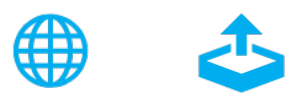

\section{ARTICLES YOU MAY BE INTERESTED IN}

Polarization mechanisms and structural rearrangements in thermally poled sodium-alumino phosphate glasses

Journal of Applied Physics 107, 043505 (2010); https://doi.org/10.1063/1.3305318

Effect of sodium addition and thermal annealing on second-order optical nonlinearity in thermally poled amorphous $\mathrm{Ta}_{2} \mathrm{O}_{5}$ thin films

Journal of Applied Physics 125, 015104 (2019); https://doi.org/10.1063/1.5054857

Enhanced Raman scattering in thermally poled sodium-niobium borophosphate glasses

Journal of Applied Physics 101, 083532 (2007); https://doi.org/10.1063/1.2724798

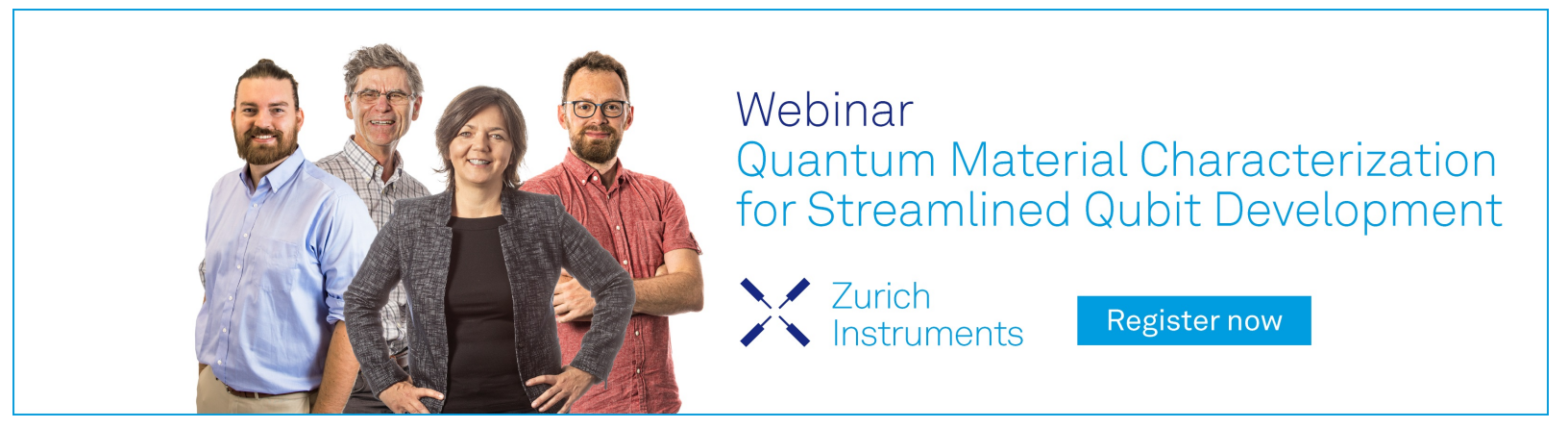




\title{
Large scale micro-structured optical second harmonic generation response imprinted on glass surface by thermal poling
}

\author{
G. Yang,,${ }^{1,2,3}$ M. Dussauze, ${ }^{1, a)}$ V. Rodriguez, ${ }^{1}$ F. Adamietz, ${ }^{1}$ N. Marquestaut, ${ }^{4}$ \\ K. L. N. Deepak, ${ }^{5}$ D. Grojo, ${ }^{5}$ O. Uteza, ${ }^{5}$ P. Delaporte, ${ }^{5}$ T. Cardinal, ${ }^{2}$ and E. Fargin ${ }^{2}$ \\ ${ }^{1}$ University of Bordeaux, ISM, CNRS UMR 5255, F-33400 Talence, France \\ ${ }^{2}$ University of Bordeaux, ICMCB, CNRS UPR 9048, F-33600 Pessac, France \\ ${ }^{3}$ School of Materials Science and Engineering, Shanghai University, Shangda Rd. 99, Baoshan, \\ Shanghai 200444, China \\ ${ }^{4}$ University of Bordeaux, LOMA, CNRS UMR 5798, F-33400 Talence, France \\ ${ }^{5}$ Aix-Marseille University, CNRS, LP3 UMR 7341, F-13288 Marseille, France
}

(Received 12 May 2015; accepted 4 July 2015; published online 24 July 2015)

\begin{abstract}
Micro-structured second harmonic generation responses have been achieved on borophosphate niobium glasses by thermal poling using micro-patterned silicon substrates. The poling imprinting process has created sub-micrometer sized patterns of both surface relief and second order optical responses on the anode glass surface. Field enhancement effects within the micro structured electrode are believed to govern the charge density on the glass surface during the process and thus amplitudes of both implemented electric field and Maxwell stresses. (C) 2015 AIP Publishing LLC.

[http://dx.doi.org/10.1063/1.4926866]
\end{abstract}

\section{INTRODUCTION}

Thermal poling has been widely studied to induce second order optical properties such as second harmonic generation (SHG) in glasses. ${ }^{1-3}$ In the majority of poled glassy systems, the SHG response is a classic electric fieldinduced second harmonic (EFISH) effect, resulting from the interaction of a "frozen" space charge and the third-order optical susceptibility: $\chi^{(2)}=3 \chi^{(3)} \mathrm{E}_{\text {stat }}$. Applying this polarization process to silica fibers or waveguides has notably permitted the successful fabrication of several glass-based electro optical converters. ${ }^{4-9}$ To improve the $\chi^{(2)}$ efficiency of poled glasses, important efforts have been done to engineer new chemical compositions with high $\chi^{(3)}$ values, which could support the implementation of a strong and stable space charge. Promising properties have been reported for several oxide and chalcogenide compositions exhibiting effective $\chi^{(2)}$ values in the range of 1 to $10 \mathrm{pm} / \mathrm{V} \cdot{ }^{10-14}$ All these results demonstrate the real potential of polarized glassy systems for photonic applications. Nevertheless, the main issue to be addressed in the future concerned the control of the space charge implementation at micrometer or sub-micrometer scales. The principal methodologies tested in order to structure spatially the second order nonlinearity (SONL) of poled glasses are mainly based on a local erasure of the space charge or on the use of micro structured embedded electrodes. ${ }^{15,16}$ Among all these results, one should also point out the possibility to use thermal poling on femtosecond irradiated glasses for which the SHG response is locally enhanced within the irradiated zone. ${ }^{17-19}$ In this study, we report on the ability of a thermal poling treatment to be considered as an imprinting process modifying both nonlinear

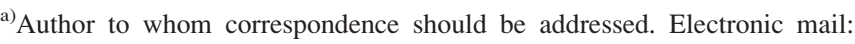
marc.dussauze@u-bordeaux.fr
}

optical properties and surface morphology using a patterned silicon electrode.

\section{EXPERIMENTAL}

Bulk niobium borophosphate glass samples with a composition of $0.58\left(0.95 \mathrm{NaPO}_{3}+0.05 \mathrm{Na}_{2} \mathrm{~B}_{4} \mathrm{O}_{7}\right)+0.42 \mathrm{Nb}_{2} \mathrm{O}_{5}$ have been prepared with conventional melt quenching method as reported elsewhere. ${ }^{13}$ Thermal poling was done under $\mathrm{Ar}$ at atmospheric pressure. The glass samples were heated at the temperature of $230^{\circ} \mathrm{C}$ for at least $1 \mathrm{~h}$ before applying a DC voltage of $2.0 \mathrm{kV}$ for $30 \mathrm{~min}$. Samples were previously cooled down to room temperature before removing the external electric field. At the anode, silicon substrates with sub-micron size micro-craters were used as the electrode. They were fabricated by an innovative laser ablation technique using Langmuir films of microspheres as a periodically focusing optical element to achieve directly a long range nano-patterning of silicon surfaces. All technical details have been reported elsewhere. ${ }^{19}$ At the cathode, a $100 \mu \mathrm{m}$ thick borosilicate glass has been used as a nonblocking electrode to avoid the reduction of niobium.

AFM measurements were done on both the anode electrode and poled glass surfaces using the non-contact mode of an Agilent Technologies system.

Two sets of macroscopic SHG measurements were done in the transmission mode: first, a scanning of the incident angle with a fixed incident polarization (classical Maker fringes) and, second, a continuous polarization scan of the input beam at a fixed incidence angle. In the latter set, the fundamental beam, initially polarized out of the plane of incidence, is passed through a combination of a rotating half wave plate and a fixed quarter wave plate (vertical fast axis) to address all possible polarizations from linear to elliptical and to circular polarization. The incident beam is focused on 
the sample with a spot size of $100 \mu \mathrm{m}$ and the transmitted second harmonic light is resolved into components polarized parallel (p) and perpendicular (s) to the horizontal plane of incidence. These analyses were performed using a spectral physics Nd:YAG laser $1064 \mathrm{~nm}, 20 \mathrm{~Hz}, 20 \mathrm{~ns}$ pulses with a typical energy of $250 \mu \mathrm{J}$.

SHG microscopy was carried out in both transmission and reflection modes. In both cases, a radial polarization mode obtained from polarization converters (provided by Arcoptix) has been used. Such a radial "donut" polarization mode allows to probe the longitudinal component of the induced electric field at the focal point. In the transmission mode, the experimental nonlinear imaging setup was based on a home-made nonlinear microscope including a fs laser (KGW:Yb oscillator, $1 \mathrm{~W}, 50 \mathrm{MHz}$, typically 200 fs at $1030 \mathrm{~nm}$, T-Pulse 20, Amplitude Systemes), a half-wave plate before a Faraday rotator to isolate the laser from beam reflection and to control the irradiance of the laser pulses, an adapted pair of GTI (Gires-Tournois interferometer) mirrors to compensate the Faraday rotator group velocity dispersion, a polarization filter, a loosely focusing objective preventing significant longitudinal polarization at the focus (Olympus, $10 \times$, NA 0.25 ) followed by a sharp collecting objective (Olympus, $100 \times$, NA 0.8 ), a polarization analyzer and a spectral bandpass filter centered at $515 \mathrm{~nm}$ for the analysis of the SHG signal, and, finally, a Peltier-cooled high-sensitivity CCD camera (Hamamatsu C4742-95), as seen in Fig. 1. The sample position between the two objectives was adjusted with a high precision 2D translation stage in the horizontal plane (Newport, SMC100) and with a manual microprecision controlled for longitudinal displacement. Second harmonic signal was obtained by numerically integrating the pixels of the images of the nonlinear emitting patterns, once these images were properly conjugated and obtained on the CCD camera. The fundamental and second-harmonic radiation spectra have been controlled with a fiber spectrometer.

(A)

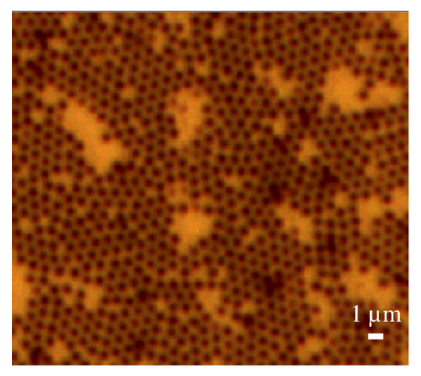

(B)
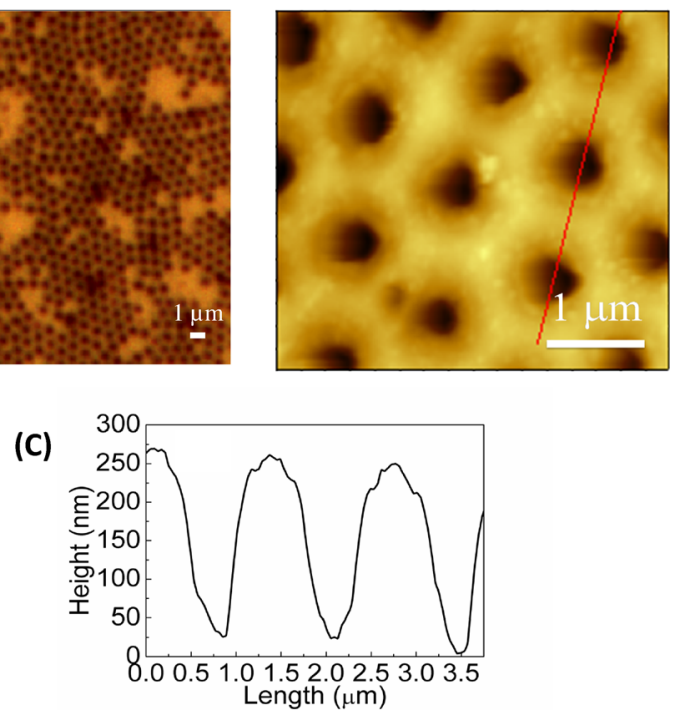

FIG. 1. Optical image of the silicon electrode (a). Topology AFM image (b) and spatial profile (c) (corresponding to the red line on the 2D image) measured on the silicon electrode.
SHG microscopy in reflection mode has been carried out using a modified Raman confocal microscope spectrometer HR800 Horiba/Jobin-Yvon. A Nd:yttrium aluminum garnet Nd:YAG EKSPLA picosecond laser $1064 \mathrm{~nm}, 2 \mathrm{kHz}, 65 \mathrm{ps}$ pulses with a typical energy less than $50 \mu \mathrm{J}$ and a $130 \times$ immersion objective with a numerical aperture of 1.3 has been used.

\section{RESULTS AND DISCUSSION}

The silicon electrode surface is depicted in Figs. 1(a)-1(c). One should notice that the overall patterned electrode surface sized few square millimeters. The optical image (Fig. 1(a)) shows a typical micro patterned region of $625 \mu \mathrm{m}^{2}$. It permits to clearly discern the spatial distribution of the micro craters formed on the electrode. More than $70 \%$ of the millimeter size electrode surface was structured with a homogeneity that depends directly on the quality of the glass microsphere film obtained during the fabrication process. ${ }^{20}$ The AFM measurements, depicted in Figs. 1(b) and 1(c), permit to focus on the topology of the silicon structuration. It shows that regular hexagonal patterns have been obtained. The spatial profile measured on the electrode reveals a periodicity of $1.3 \mu \mathrm{m}$ corresponding to the diameter of the microspheres used in the laser patterning experiment. The average diameters and depths of micro-craters are $0.7 \mu \mathrm{m}$ and $250 \mathrm{~nm}$, respectively.

As previously reported in the literature, we expect a modification of the glass topology after the poling process. ${ }^{21-23}$ On the imprinted glass surface, a pattern similar to the silicon electrode can be observed by optical microscopy in Fig. 2(a). The surface morphology induced on the poled glass has been characterized by AFM imaging as shown in Fig. 2(b). The corresponding spatial profile denotes the same
(A)

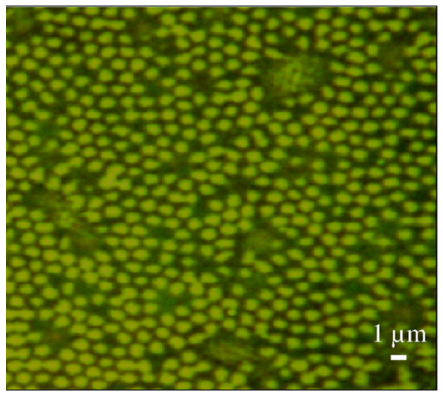

(C)
(B)

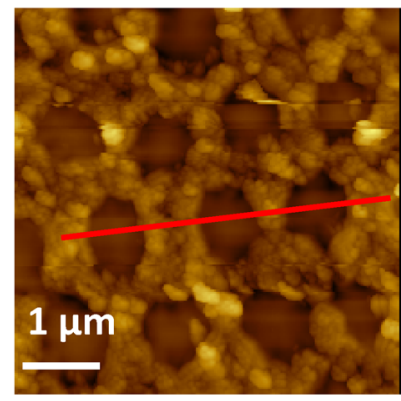

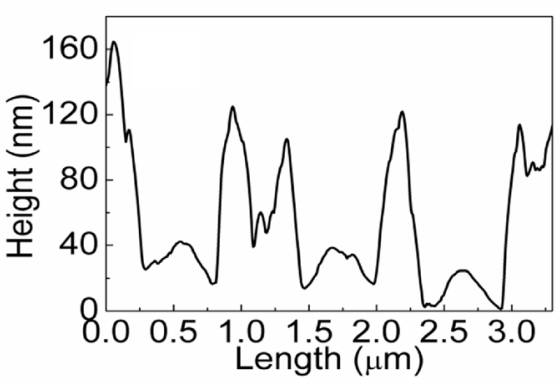

FIG. 2. Optical image (a) and topology AFM images (b) of the poled glass surface. Spatial profile (c) (corresponding to the red line on the 2D image). 
periodicity that was observed on the electrode. However, the shape induced by the polarization treatment is more complex than the morphology imprinted on the silicon substrate. In correspondence to the anode micro-craters, a decrease of the glass relief is observed forming an almost cylindrical shape closed at the bottom by a smooth and curved relief increase of 20 to $30 \mathrm{~nm}$. One should also notice that the roughness of the glass surface has increased at the boarders of the halls forming hexagonal patterns.

In the first step, the averaged macroscopic second order optical response induced by the poling treatment has been characterized quantitatively by the classical Maker fringes technique. To perform a quantitative analysis of the $\chi^{(2)}$ tensor components, a complete Maker fringes analysis using both rotation scans of the samples $(\theta$ scans; Figure 3(b) upper part) with a fixed laser polarization and laser polarization scans with a fix angle of incidence ( $\psi$ scans; Figure 3(b) lower part) has been performed. For each of these experiments, the transmitted SHG signal was resolved into components polarized parallel $(\mathrm{p})$ or perpendicular $(\mathrm{s})$ to the plane of incidence. This procedure contains four separate experiments that have been fitted simultaneously using the same set of parameters and an optical model based on an optical transfer matrix procedure. ${ }^{24}$ Inputs to the optical model are (i) refractive indices at $\omega$ and $2 \omega$ measured independently using the Brewster angle technique and (ii) the thickness of the nonlinear optical layer measured using confocal second harmonic generation microscopy (see Figure 3(a)).

Fitting results show that the $\chi^{(2)}$ tensor obeys to a macroscopic $\mathrm{C}_{\infty} \mathrm{V}$ symmetry with a ratio of the components $\chi^{(2)}{ }_{\mathrm{zzz}}=1 / 3 \cdot \chi_{\mathrm{zxx}}^{(2)}$, confirming a pure EFISH response. Quantitatively, an average $\chi^{(2)}$ efficiency of $2 \mathrm{pm} / \mathrm{V}$ has been estimated. Knowing the $\chi^{(3)}$ value of this glass composition, ${ }^{25}$ it is then possible to estimate a macroscopic averaged strength of the implemented electric field greater than $10^{8} \mathrm{~V} / \mathrm{m}$.
In the second step, we focus our attention on the spatial distribution of the implemented space charge by SHG mapping carried out either in transmission or in reflection mode. We remind that in both cases, a radial polarization mode has been used in order to probe at the focal point the longitudinal component of the induced electric field (i.e., the $\chi^{(2)}{ }_{z z z}$ component as confirmed by the Maker fringes analysis detailed above). On the transmission SHG image shown in Fig. 4, we clearly observe a structuration of the optical signal on the entire glass surface. In several zones, one can recognize hexagonal patterns; in the other areas, the SHG signals are generally higher within spots that are interconnected forming lines and curves. The typical distances between spots of higher SHG signal are always in the range of 1 to $1.5 \mu \mathrm{m}$, which corresponds well to the distance between the craters measured by AFM on both patterned silicon electrode and glass surface.

To further characterize the implemented static electric field spatial distribution, we have carried out SHG measurements in reflection mode with an oil immersion objective (NA 1.3) allowing a better spatial resolution. In Fig. 5, one can compare an optical picture of the poled glass surface and its corresponding SHG map. On the optical image, one hexagonal pattern can be recognized, and the corresponding SHG map depicts clearly seven spots with a higher SHG response, which could be correlated to the seven craters observed on the optical image. Moreover, the SHG image also shows clear differences as compared to the optical image notably linked to interconnections formed between some of the spots having a higher response.

Finally, a tentative of correlation between electrode topology and SHG spatial responses can be done. It appears that at the position of the electrode's craters, the SHG response is higher. Such an observation gives a first insight concerning the physical origin of the implemented electric field spatial structuration. Notably, a simple electrostatic
(A)

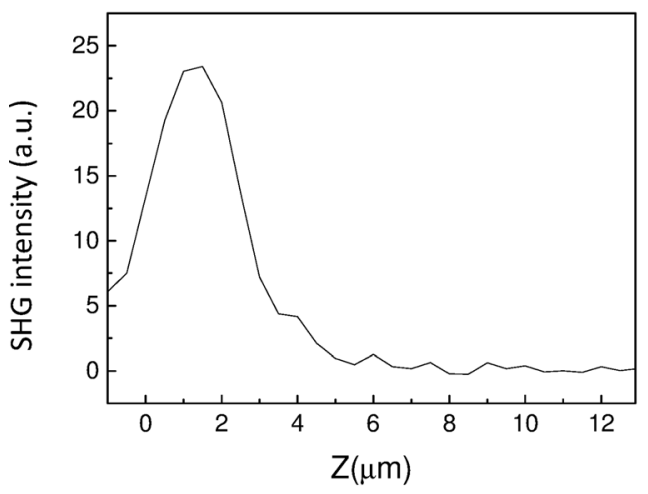

(B)

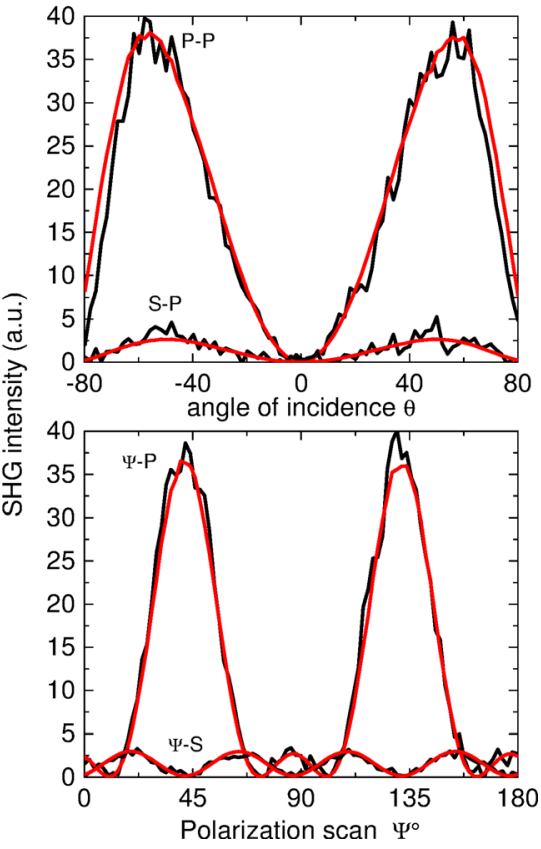

FIG. 3. (a) Depth profile of SHG measured by SHG confocal microscopy $(0 \mu \mathrm{m}$ is assigned to the surface $\pm 0.5 \mu \mathrm{m})$. (b) (Up) Experimental (black) and calculated (red) profiles for transmitted p-p (s-p) polarized Maker fringe pattern and (b) polarization scan patterns $\Psi$-p $(\Psi-s)$ obtained at an incident angle of $60^{\circ}$. 


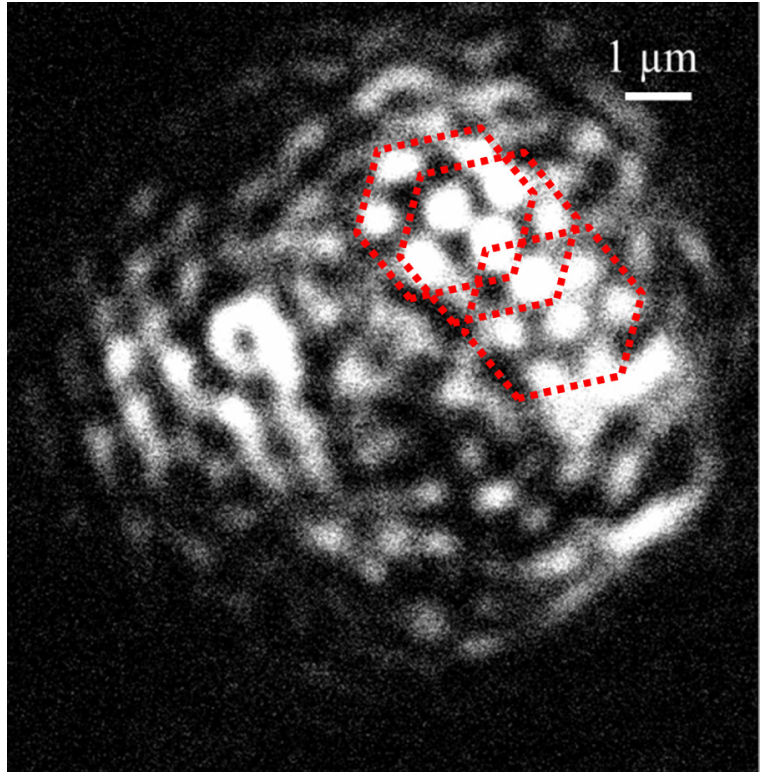

FIG. 4. SHG mapping of an imprinted poled glass anodic surface measured in transmission mode.

model taking into account an electrical potential on the glass surface governed by the distance electrode/glass predicts the opposite trends, that is, a minimum of SHG at the position of the silicon electrode craters, ${ }^{26}$ as compared to what have been observed experimentally in our study. To better

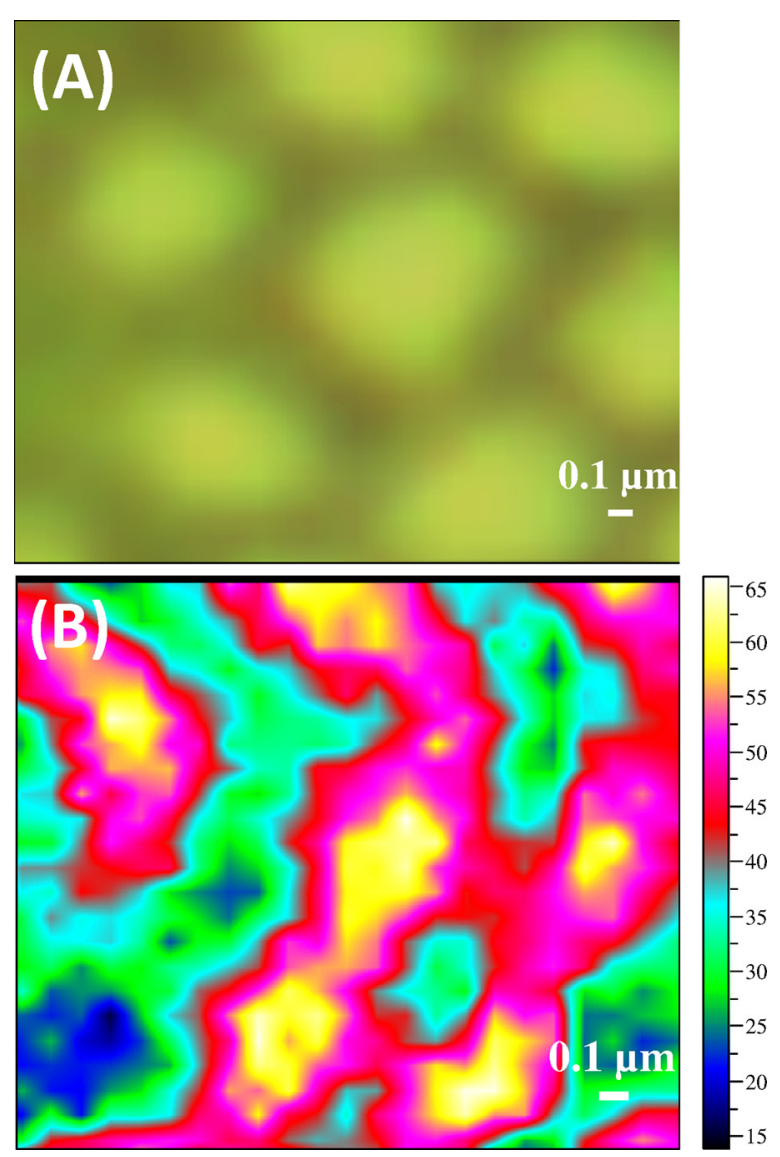

FIG. 5. (a) Optical images of the polarized glass surface and (b) corresponding micro-SHG signal measured in reflection mode. describe a thermal poling process using a structured electrode, other parameters should be taken into account. It is our opinion that depending on the electrode shape, one should take into account the field enhancement effect induced by spatial confinement. AFM data permit to estimate the curve radius at the bottom of the silicon electrode craters in the range of 50 to $100 \mathrm{~nm}$. As a comparison, a corona poling procedure that is based on local field enhancement uses tips or strings whose sizes are in the order of few tens of micrometers. Additionally, during the poling treatment of ionic rich glasses, gas discharges occur between the anode electrode and the glass surface. The emission spectrum of the induced argon plasma is depicted in Fig. 6. Such glow or streamer discharges are typical of corona or dielectric barrier discharge (DBD) processes inducing "cold" non equilibrium plasma at atmospheric pressure. For dielectric barrier discharge, previous works have shown that the electrode shape influences largely the location of gas discharges but also their number and the induced electrical current intensity. ${ }^{27,28}$ Concerning thermal poling process, such gas discharges have been observed for ionic rich glasses. ${ }^{29}$ Notably, a clear correlation between the intensity of the plasma emission measured during the poling treatment and the second order optical responses of the polarized glass has been reported by Moura et al. ${ }^{30,31}$ Finally, one may expect that the charge distribution on the glass surface could be controlled by local gas discharge favored by field enhancement effect.

The last part of the discussion concerns the glass surface topology modification induced by the poling imprinting process on such an ionic rich glass. For a similar polarization treatment achieved on silicate glasses, Brunkov et al. have supposed that the glass surface deformation is due to internal stresses arising in the glass matrix after electricfield-induced ions exchange. ${ }^{20,21}$ The magnitude of such internal stresses has been estimated one order of magnitude higher than the Maxwell stress expected in their polarization conditions. $^{20,21}$

In our poling conditions, the treatment is done under argon atmosphere for which one can neglect a possible

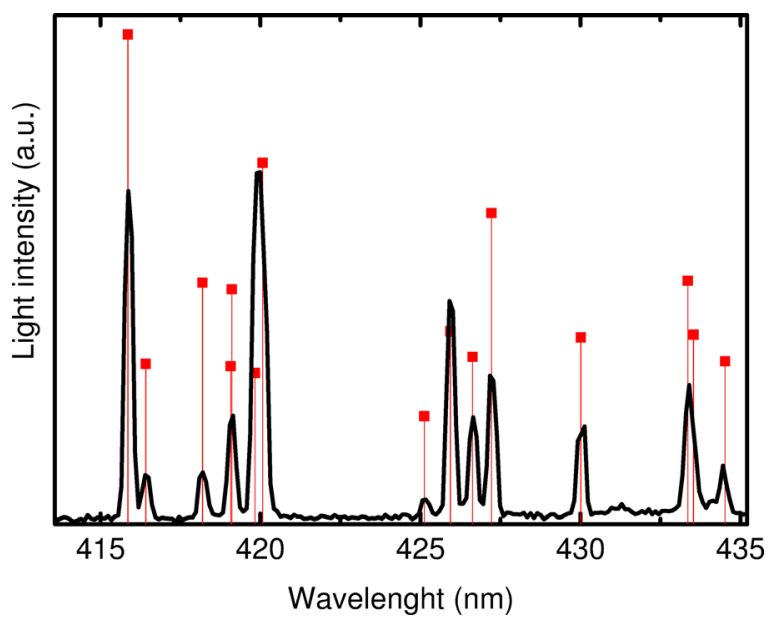

FIG. 6. Emission spectra of the argon plasma measured at glass anode interface. Red dots/lines are the expected emission lines from the INIST database. 
spatially selective ion exchange linked to the electrode shape. Structural changes induced by the sodium depletion were characterized using micro Raman (not shown here). The observed modification was in accordance to our previous reports ${ }^{32}$ and was spatially uniform. It tends to prove that for our poling conditions (i.e., mainly the electrode shape and poling atmosphere), spatial composition variations could not be observed, and as a consequence, the internal stresses induced by the sodium depletion linked to structural rearrangement should likely represent a minor contribution. However, because of the electrode shape, field enhancement effects could induce local variation of the charge surface density, which could govern both the amplitude of the internal field implemented and the amplitude of the Maxwell stress. The spatial correspondence observed between active SHG spots and higher decrease of the surface topology might confirm our hypothesis.

\section{CONCLUSION}

Using micro-patterned silicon substrates as anodic electrode for a thermal electric field imprinting technique, we have demonstrated the possibility to fabricate millimeter sized glass surfaces with micrometer-scale patterns of both surface topology and second order optical properties. Through analyses of AFM, high resolution SHG imaging, and in-situ plasma emission characterization, we have pointed out the importance of field enhancement effects within the micro structured electrode, which could govern the charge density on the glass surface during the process and thus locally modify the amplitudes of both implemented electric field and Maxwell stress.

\section{ACKNOWLEDGMENTS}

This work was supported by the French Agency of National Research [ANR 2010 BLAN 94603, ANR-2010 JCJC-0806 01], the French Aquitaine region [Grant FELINS and Grant 20121101025], and the laboratory of Excellence Laphia. G.Y. thanks The Young Eastern Scholars 2015 supported by Shanghai City Board of Education.

${ }^{1}$ R. A. Myers, N. Mukherjee, and S. R. J. Brueck, "Large second-order nonlinearity in poled fused silica," Opt. Lett. 16, 1732-1734 (1991).

${ }^{2}$ T. G. Alley, S. R. J. Brueck, and R. A. Myers, "Space charge dynamics in thermally poled fused silica," J. Non-Cryst. Solids 242, 165-176 (1998).

${ }^{3}$ M. Dussauze, T. Cremoux, F. Adamietz, V. Rodriguez, E. Fargin, G. Yang, and T. Cardinal, "Thermal poling of optical glasses: Mechanisms and second-order optical properties," Int. J. Appl. Glass Sci. 3, 309-320 (2012).

${ }^{4}$ M. Fokine, L. E. Nilsson, ̊̊. Claesson, D. Berlemont, L. Kjellberg, L. Krummenacher, and W. Margulis, "Integrated fiber Mach-Zehnder interferometer for electro-optic switching," Opt. Lett. 27, 1643-1645 (2002).

${ }^{5}$ G. Li, K. A. Winick, A. A. Said, M. Dugan, and P. Bado, "Quasi-phase matched second-harmonic generation through thermal poling in femtosecond laser-written glass waveguides," Opt. Express 17, 9442-9453 (2009).

${ }^{6}$ J. Fage-Pedersen, R. Jacobsen, and M. Kristensen, "Planar glass devices for efficient periodic poling," Opt. Express 13, 8514-8519 (2005).

${ }^{7}$ J. Fage-Pedersen, R. Jacobsen, and M. Kristensen, "Poled-glass devices: influence of surfaces and interfaces," J. Opt. Soc. Am. B 24, 1075-1079 (2007).

${ }^{8}$ N. Myren and W. Margulis, "All-fiber electrooptical mode-locking and tuning,” IEEE Photonics Technol. Lett. 17, 2047-2049 (2005).
${ }^{9}$ W. Margulis, O. Tarasenko, and N. Myrén, "Who needs a cathode? Creating a second-order nonlinearity by charging glass fiber with two anodes," Opt. Express 17, 15534-15540 (2009).

${ }^{10}$ M. Guignard, V. Nazabal, F. Smektala, J. L. Adam, O. Bohnke, C. Duverger, A. Moréac, H. Zeghlache, A. Kudlinski, G. Martinelli, and Y. Quiquempois, "Chalcogenide glasses based on germanium disulfide for second harmonic generation," Adv. Funct. Mater. 17, 3284-3294 (2007).

${ }^{11}$ J. Ren, G. Yang, H. Zeng, G. Chen, K. Tanaka, K. Fujita, S. Murai, and Y. Tsujiie, "Second-harmonic generation in thermally poled chalcohalide glass," Opt. Lett. 31, 3492-3494 (2006)

${ }^{12}$ K. Tanaka, A. Narazaki, and K. Hirao, "Large optical second-order nonlinearity of poled $\mathrm{WO}_{3}-\mathrm{TeO}_{2}$ glass," Opt. Lett. 25, 251-253 (2000).

${ }^{13}$ M. Dussauze, E. Fargin, A. Malakho, V. Rodriguez, T. Buffeteau, and F. Adamietz, "Correlation of large SHG responses with structural characterization in borophosphate niobium glasses," Opt. Mater. 28, 1417-1422 (2006).

${ }^{14}$ M. Dussauze, E. Fargin, M. Lahaye, V. Rodriguez, and F. Adamietz, "Large second-harmonic generation of thermally poled sodium borophosphate glasses," Opt. Express 13, 4064-4069 (2005).

${ }^{15}$ V. Pruneri, G. Bonfrate, P. G. Kazansky, D. J. Richardson, N. G. Broderick, J. P. de Sandro, C. Simonneau, P. Vidakovic, and J. A. Levenson, "Greater than 20\%-efficient frequency doubling of 1532-nm nanosecond pulses in quasi-phase-matched germanosilicate optical fibers," Opt. Lett. 24, 208-210 (1999).

${ }^{16}$ S. Chao, H.-Y. Chen, Y.-H. Yang, Z.-W. Wang, C. Shih, and H. Niu, "Quasi-phase-matched second-harmonic generation in Ge-ion implanted fused silica channel waveguide," Opt. Express 13, 7091-7096 (2005).

${ }^{17}$ C. Corbari, J. D. Mills, O. Deparis, B. G. Klappauf, and P. G. Kazansky, "Thermal poling of glass modified by femtosecond laser irradiation," Appl. Phys. Lett. 81, 1585-1587 (2002).

${ }^{18}$ A. Delestre, M. Lahaye, E. Fargin, M. Bellec, A. Royon, L. Canioni, M. Dussauze, F. Adamietz, and V. Rodriguez, "Towards second-harmonic generation micropatterning of glass surface,” Appl. Phys. Lett. 96, 091908 (2010).

${ }^{19}$ H. An, A. Arriola, S. Gross, A. Fuerbach, M. J. Withford, and S. Fleming, "Creating large second-order optical nonlinearity in optical waveguides written by femtosecond laser pulses in boro-aluminosilicate glass," Appl. Phys. Lett. 104, 021113 (2014).

${ }^{20}$ L. N. D. Kallepalli, D. Grojo, L. Charmasson, P. Delaporte, O. Utéza, A. Merlen, A. Sangar, and P. Torchio, "Long range nanostructuring of silicon surfaces by photonic nanojets from microsphere Langmuir films," J. Phys. D: Appl. Phys. 46, 145102 (2013).

${ }^{21}$ P. N. Brunkov, V. G. Melekhin, V. V. Goncharov, A. A. Lipovskii, and M. I. Petrov, "Submicron-resolved relief formation in poled glasses and glassmetal nanocomposites," Tech. Phys. Lett. 34, 1030-1033 (2008).

${ }^{22}$ P. Brunkov, V. Goncharov, V. Melehin, A. Lipovskii, and M. Petrov, "Submicron surface relief formation using thermal poling of glasses," e-J. Surf. Sci. Nanotechnol. 7, 617-620 (2009).

${ }^{23}$ T. Hideki, M. Shin-ichi, T. Masaharu, and M. Ryutaro, "Electrostatic imprint process for glass," Appl. Phys. Express 1, 024003 (2008).

${ }^{24} \mathrm{~V}$. Rodriguez and C. Sourisseau, "General maker-fringe ellipsometric analyses in multilayer nonlinear and linear anisotropic optical media," J. Opt. Soc. Am. B 19, 2650-2664 (2002); V. Rodriguez, "Quantitative determination of linear and second-harmonic generation optical effective responses of achiral or chiral materials in planar structures: Theory and materials," J. Chem. Phys. 128, 064707 (2008).

${ }^{25}$ T. Cardinal, E. Fargin, G. Le Flem, and S. Leboiteux, "Correlations between structural properties of $\mathrm{Nb}_{2} \mathrm{O}_{5}-\mathrm{NaPO}_{3}-\mathrm{Na}_{2} \mathrm{~B}_{4} \mathrm{O}_{7}$ glasses and nonlinear optical activities," J. Non-Cryst. Solids 222, 228-234 (1997).

${ }^{26}$ K. Sokolov, V. Melehin, M. Petrov, V. Zhurikhina, and A. Lipovskii, "Spatially periodical poling of silica glass," J. Appl. Phys. 111, 104307 (2012).

${ }^{27}$ Y. Kuroda, Y. Kawada, T. Takahashi, Y. Ehara, T. Ito, A. Zukeran, Y. Kono, and K. Yasumoto, "Effect of electrode shape on discharge current and performance with barrier discharge type electrostatic precipitator," J. Electrostat. 57, 407-415 (2003).

${ }^{28}$ K. Takaki, M. Shimizu, S. Mukaigawa, and T. Fujiwara, "Effect of electrode shape in dielectric barrier discharge plasma reactor for NOx removal," IEEE Trans. Plasma Sci. 32, 32-38 (2004).

${ }^{29}$ T. Cremoux, M. Dussauze, E. Fargin, T. Cardinal, D. Talaga, F. Adamietz, and V. Rodriguez, "Trapped molecular and ionic species in poled borosilicate glasses: Toward a rationalized description of thermal poling in glasses," J. Phys. Chem. C 118, 3716-3723 (2014). 
${ }^{30}$ A. L. Moura, M. T. de Araujo, E. A. Gouveia, M. V. Vermelho, and J. S. Aitchison, "Deep and shallow trap contributions to the ionic current in the thermal-electric field poling in soda-lime glasses," Opt. Express 15, 143-149 (2007).

${ }^{31}$ A. L. Moura, E. M. Nascimento, M. T. Araujo, M. V. D. Vermelho, and J. S. Aitchison, "Voltage threshold-like evidence during thermal-electric field induction of second order nonlinearity in soda-lime glasses," J. Appl. Phys. 105, 036106 (2009).

${ }^{32}$ M. Dussauze, E. Fargin, V. Rodriguez, A. Malakho, and E. Kamitsos, "Enhanced Raman scattering in thermally poled sodiumniobium borophosphate glasses," J. Appl. Phys. 101, 083532 (2007). 